\title{
Método para la determinación analítica de sulfuros $y$ de azufre total contenidos en áridos y hormigones, y consideraciones acerca de la necesidad de separar, del valor de azufre total tolerable en los áridos, el debido a la presencia de sulfuros
}

F. COMA

Director del Laboratorio de la Zona de Cataluña de la Compañía Gral. de Asfaltos y Portland ASLAND

\section{R E S U M E N}

Se describe un procedimiento de análisis químico para la determinación de sulfuros y su diferenciación del azufre total contenido en áridos y hormigones empleado por el autor para la diagnosis de las anomalías producidas en el hormigón por la presencia de estas sustancias. Se describe su identificación petrográfica y se propone la conveniencia de diferenciar, en el resultado del análisis de los compuestos de azufre, los sulfuros de los sulfatos para poder establecer sús valores límites respectivos de tolerancia.

\section{N T R O D U C C I O N}

Tuvimos la ocasión de detectar la presencia de sulfuros en los áridos y en el hormigón que fueron utilizados en la obra del edificio D.O.D., construido en 1970 para un patronato de Mataró y comarca, cuyos antecedentes e información completa fue publicada por el I.E.T.c.c. en "Materiales de Construcción. Ultimos Avances", n. ${ }^{\text {ss }}$ 150-151, en 1973 (1).

En los trabajos allí expuestos se ponía de relieve el aspecto de la inseguridad que ofrecen, para la determinación analítica de sulfuros, aquellos procedimientos que emplean ataques previos con ácidos fuertes (2) porque pueden volatilizar parcialmente una notable cantidad de este azufre en forma de ácidos sulfhídrico o sulfuroso por desplazamiento con ácido fuerte, y dar en consecuencia resultados considerablemente bajos.

La necesidad, pues, de disponer de procedimientos adecuados para estas determinaciones, el creciente interés que ha tenido este tipo de ensayos en nuestros laboratorios, así como de los métodos que utilizamos, nos ha llevado a hacer esta breve exposición del procedimiento que habíamos empleado para aquellos dictámenes y que no se expuso en aquella publicación citada (1) porque trataba el tema desde otros puntos de vista distintos al del análisis químico. 


\section{Consideraciones del procedimiento adoptado a la luz de los antecedentes bibliográficos}

Una revisión de la información bibliográfica sobre esta determinación analítica, aunque no exhauxtiva pero sí atenta a los métodos clásicos dados para ello, nos ha llevado a las siguientes consideraciones que exponemos a continuación:

Las formas más usuales en que se presentan los sulfuros en los áridos son las pertenecientes a los grupos de: blenda, würtzita, calcopirita, niquelina, pirrotina, galena y el de piritas, marcasitas (3). Por su forma ofrecen una contaminación desigualmente repartida en los áridos y, por lo tanto, también en el hormigón en los que aparecen diseminados en nódulos dispersos. Ello da lugar, en ambos tipos de materiales, a que la toma de muestra que se hace para su análisis presente la dificultad de tener forzosamente que partir de cantidades mayores de lo común para que aquélla llegue a ser representativa. Por otra parte, el mayor peso específico de estos minerales ofrece el peligro de la clasificación en el manejo de los cuarteos cuando la granulometría no es adecuadamente fina y uniforme.

Los métodos para la determinación química basados en el ataque directo con ácidos fuertes (4) ofrecen la duda que la descomposición de los sulfuros y sulfitos insolubles no sea total (5) y (6), razón por la que hemos adoptado la disgregación alcalina. Esta la realizamos en crisol de oro con hidróxido sódico y peróxido sódico $(2: 1)$, aunque nos ha dado buenos resultados la disgregación en crisol de hierro o níquel (10).

La temperatura adecuada para la disgregación es generalmente de unos $400^{\circ} \mathrm{C}$ como máximo y la duración del ataque, en la mayoría de los casos, es de unos 10 minutos. Cuando la temperatura es más alta que la indicada, trabajando con crisol de oro, se tiene ya un sensible ataque del crisol que alcanza unos pocos mg.

Una vez frío el crisol que contiene el disgregado se disuelve en agua caliente (en lugar de ácido) a una temperatura no superior a $\operatorname{los} 40^{\circ} \mathrm{C}$ y se procede a la oxidación con agua de bromo, en este medio fuertemente alcalino, introduciendo el oxidante en frío para evitar su volatilización antes de oxidar. Esta segunda oxidación es necesaria para asegurar que todo el azufre ha conseguido su estado de valencia VI antes de pasar a medio ácido y ha sido también seguida por otros autores (7).

Obtenidos el ataque alcalino, la disolución de la muestra en agua y la oxidación de la misma en medio alcalino, se pasa la solución a medio ácido con ácido clorhídrico y hacemos la separación previa de la sílice antes de la precipitación del ion sulfato por el cloruro de bario para impedir que, una formación accidental de sílice precipitada durante los tratamientos en medio ácido por la polimerización de los ácidos silícicos, impurifique los precipitados de sulfato de bario. Otros autores han tenido en cuenta esta misma precaución (8) y (9) y justificada aquí con mayor razón cuando el contenido en sílice, en este tipo de materiales, es mayoritariamente silíceo.

En cuanto a la precipitación del ion sulfato con cloruro de bario, lo hemos efectuado de la forma usual tan sólo remarcando la necesidad de proceder a la precipitación, sin parar el estado de ebullición, por el empleo de las dos soluciones precipitantes hirvientes y la de recurrir a una maceración del precipitado a $90^{\circ} \mathrm{C}$ durante 2 ó 3 horas como mínimo.

\section{Procedimiento que hemos adoptado}

El procedimiento seguido, partiendo de una muestra representativa y homogeneizada, ha sido el siguiente:

Se toma $1 \mathrm{~g}$ de muestra, molturada a un tamaño de partícula comprendido entre las 60 y 90 micras, se colocan $4 \mathrm{~g}$ de hidróxido sódico en lentejas y $1 \mathrm{~g}$ de peróxido sódico en un crisol de oro. 
Se funde cuidadosamente sobre mechero de Bunsen evitando que la llama pueda introducir azufre del gas en la muestra. Generalmente con una temperatura del orden de los $400^{\circ} \mathrm{C}$ se consigue un ataque completo de la muestra. Una vez frío el crisol se introduce dentro de una cápsula de platino (o porcelana) con unos $40 \mathrm{ml}$ de agua caliente a unos $40^{\circ} \mathrm{C}$, se mantiene hasta su disolución total y se retira el crisol. Luego se enfría a la temperatura ambiente; se vierten $5 \mathrm{ml}$ de solución saturada de bromo; se calienta lentamente y se hierve hasta eliminación del bromo. Se enfría y se añade ácido clorhídrico 1:1 hasta medio ácido fuerte y se adiciona aún un fuerte exceso de unos $20 \mathrm{ml}$ de clorhídrico concentrado con las debidas precauciones para evitar el desprendimiento de partículas.

Se evapora a sequedad bajo epirradiador; se procede a la insolubilización de la sílice evaporando a sequedad y se disuelve el residuo con unos $40 \mathrm{ml}$ de ácido clorhídrico diluido en la forma usual.

Se filtra, se lava, y en el filtrado se determina el ion sulfato por precipitación con cloruro de bario de la forma habitual teniendo presente de que la precipitación se haga con las dos soluciones precipitantes hirvientes y se continúe con una maceración a $90^{\circ} \mathrm{C}$ durante unas 3 horas, dejando reposar al cabo de ellas unas 12 horas, a ser posible. Se filtra y se lava con agua hasta eliminación del ion cloruro; se incinera a baja temperatura hasta combustión total del papel; se oxida con unas gotas de ácido nítrico y ácido sulfúrico; se evapora a sequedad y se calcina a la temperatura de unos $800^{\circ} \mathrm{C}$; se enfría en desecador y se pesa.

Los contenidos pequeños de sulfuro, en este tipo de materiales, hacen normalmente innecesaria una purificación del precipitado de sulfato de bario.

Se obtiene así el valor del contenido en azufre total en la muestra.

Para hallar el valor de azufre que contiene la muestra en estado hexavalente procedemos del modo siguiente:

Un gramo de la misma muestra representativa, homogeneizada y reducida al tamaño anteriormente indicado, se disgrega en crisol de hierro (en lugar de oro, para evitar en este caso la formación de la correspondiente tiosal) con $5 \mathrm{~g}$ de hidróxido sódico en lentejas sin aportación de oxidante alguno. Se funde cuidadosamente en las mismas condiciones de tiempo y temperatura indicadas antes.

Una vez frío, se disuelve en agua caliente; se retira el crisol y se ataca con ácido clorhídrico $1: 3$ en caliente, y se sigue de la misma forma que anteriormente, separando también previamente la sílice.

El resultado obtenido corresponde prácticamente al azufre que originariamente se encuentra en la muestra como hexavalente.

Al valor del contenido en azufre total, expresado en forma de $\mathrm{SO}_{3} \%$, descontamos el valor del contenido en $\mathrm{SO}_{3} \%$ que procede del azufre hexavalente y obtenemos el contenido en la muestra, en tanto por ciento, de azufre en estado de valencia inferior a VI expresado en forma de $\mathrm{SO}_{3} \%$.

\section{Comprobación experimental}

Se ha tomado una pirrotina cristalizada SFe de alto grado de pureza; se ha molturado y homogeneizado a la finura adecuada para el análisis, y se ha determinado su contenido en sulfuro por el procedimiento indicado. El valor obtenido, expresado como $\mathrm{S}^{=}$, ha sido de $36,1 \%$. Esta muestra se ha añadido en cantidades conocidas a una muestra de árido sílico-calcáreo exento de sulfuros y se ha procedido al análisis de las muestras homogeneizadas obtenidas por el procedimiento propuesto. 
Los resultados obtenidos se expresan en la siguiente tabla:

\begin{tabular}{c}
$\% \mathbf{s}^{=}$añadido \\
\hline 2,5 \\
2,8 \\
1,0 \\
0,8 \\
0,2 \\
0,1
\end{tabular}

\begin{tabular}{c}
$\% \mathbf{s}^{=}$hallado \\
\hline 2,4 \\
2,9 \\
1,0 \\
0,7 \\
0,18 \\
0,12
\end{tabular}

\begin{tabular}{c}
$\begin{array}{c}\% \mathbf{s}=\text { hallado } \\
\text { expresado como } \text { So }_{3}\end{array}$ \\
\hline 6,0 \\
7,2 \\
2,5 \\
1,7 \\
0,4 \\
0,2
\end{tabular}

Los resultados corresponden, con buena aproximación, para las pequeñas cantidades que suelen encontrarse en este tipo de determinaciones.

\section{Consideraciones acerca del contenido de sulfuros en los áridos para hormigón}

Para la identificación microscópica de las diferentes especies cristalinas de sulfuros hemos empleado un microscopio de reflexión REACHERT, Tipo MeF2, y nos ha dado excelentes resultados, por su extremado contraste de réplica, el empleo de la luz polarizada. Para la especie tratada, con el polarizador a $180^{\circ} \mathrm{C}$ y el analizador a $76^{\circ} \mathrm{C}$ se ha conseguido la máxima extinción de la luz en los materiales distintos a la pirrotina.

Los sulfuros producen en el hormigón dos tipos de fisuras: unas macroscópicas debidas a las tensiones que se producen por la oxidación de los propios nódulos expansionándose con gran incremento de volumen, y otras microfisuras en el cemento hidratado del hormigón como consecuencia de la formación de sulfatos de cal y sulfoaluminatos que redücen - como sabemos- la durabilidad del hormigón.

Algunos aspectos de las primeras los hemos detectado en el hormigón estudiado en el trabajo citado (1), de Mach y Roca, por la técnica citada, de la que reproducimos aquí algunas de las microfotografías más representativas.

Sin ataque y a bajo aumento, entre los 80 y los 144 diámetros, muestran, bajo luz normal y polarizada, la presencia de los nódulos de sulfuros de un mayor poder de reflexión con suficiente contraste con luz normal para permitir su identificación por esta técnica y con mucho mayor contraste con luz polarizada.

Las fisuras se transmiten de nódulo a nódulo en las microfotografías 1 y 3 y se observa, en aquélla, nódulos con su incipiente fragmentación expansiva por oxidación.

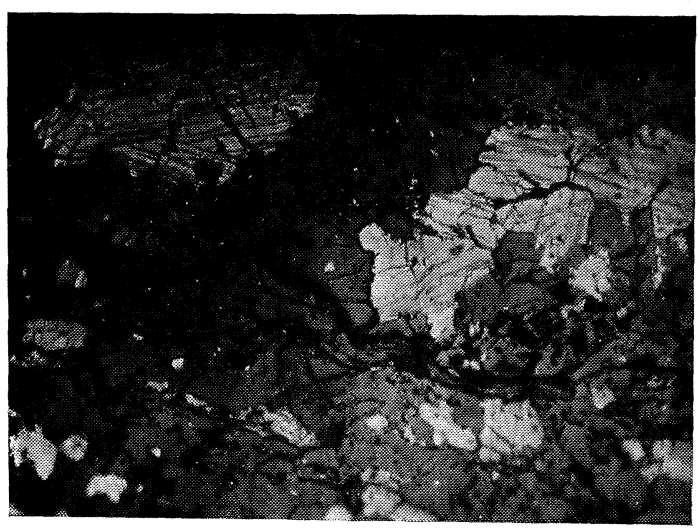

Microfotografía $1 .-144 \times \sin$ ataque: nódulos en expansión con fisuras. Luz normal.

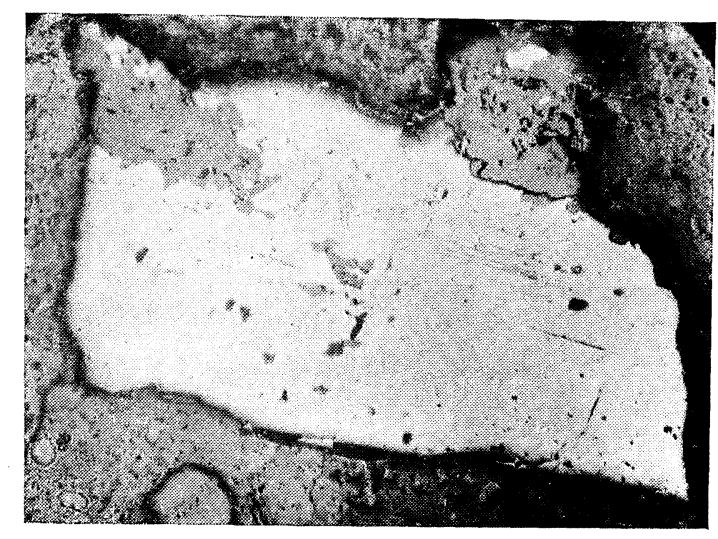

Microfotografía 2.-144 $\times$ sin ataque: nódulo aún sin grietas. Luz normal 
El valor del contenido en sulfato total, expresado como $\mathrm{SO}_{4}{ }^{2}$, comúnmente indicado de $1,2 \%$ como límite en las arenas y gravas para hormigón (11) suele proceder, en su mayor parte, del $\mathrm{SO}_{4} \mathrm{Ca} \cdot 2 \mathrm{H}_{2} \mathrm{O}$. Este se halla, en general, uniformemente repartido en la muestra por razón de su fragilidad y notable solubilidad en el agua. Por este motivo y porque no sufre una oxidación expansiva, como lo es en el caso de los sulfuros, no da lugar a este tipo de fisuras aunque sí afecta, de acuerdo con su proporción, a la durabilidad como sabemos (13), (14) y (15).

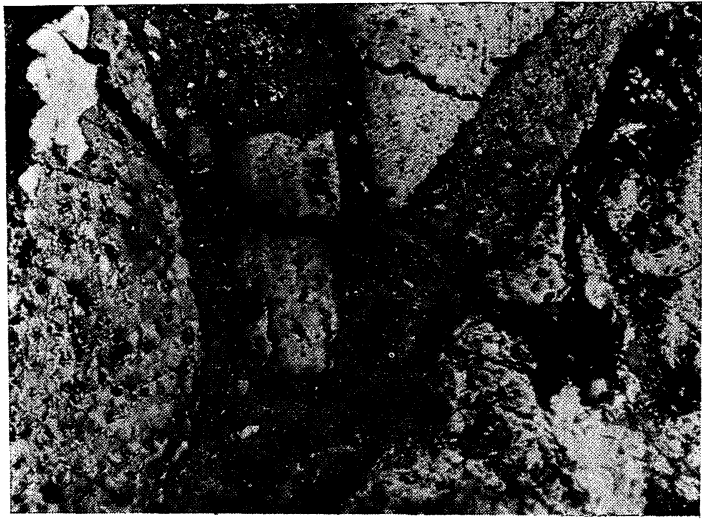

Microfotografía 3.- $80 \times$ sin ataque con luz polarizada: polarizador $180^{\circ}$ y analizador a $76^{\circ}$. - Fisura entre dos nódulos piritosos que aparecen mucho más reflectantes y contrastados bajo la luz polarizada.
En cambio, en los casos en que este contenido de $\mathrm{SO}_{4}{ }^{2}$ proceda de nodulaciones piritosas creemos, a nuestro modo de ver, que un valor aún mucho más bajo que el $1,2 \%$ previsto, es ya objetable por asegurar la formación de estas fisuras aludidas que aparecen ya a cortos plazos y por la acción nociva que el ácido sulfúrico formado tiene sobre las armaduras cuando es el caso (12).

Hemos tenido ocasión de comprobar las dudas que ello ofrece en la interpretación de los resultados de análisis y que justifican la conveniencia de establecer, tal vez, un valor límite para el contenido "exclusivo" de sulfuros, así como el de disponer de un procedimiento seguro para su determinación analítica y a cuyo fin intentamos aportar esta colaboración.

\section{B I B L I O G R A F I A}

(1) E. Mach y L. Roca Cuadrada: Materiales de Construcción, últimos avances n.os 150 y 151. "Primeras jornadas de durabilidad".

(2) "Norma UNE n. 7245 para la determinación de compuestos de azufre en áridos".

(3) M. Font-Altaba: "Atlas de mineralogía” (1974).

(4) Cembureau: "Projet de recommandations ISO 771-775" (1967).

(5) M. Groger: Ber. 24 (1937) (1891).

(6) Kolthoff-SANDELl: "Tratado de quimica anaíitica". Traducción tercera edición inglesa (1960). Página 406 .

(7) F. P. Treadwell y W. T. Hall: "Química analítica". Traducción novena edición. Pág. 365.

(8) W. W. Sсотт : "Standard Methods of Chemical Analysis, 2." edición" (1917).

(9) ARNOLd LASSIEUR: "Documents d'analyse chimique -I Analyse des silicates". Dunod 1951.

(10) L. S. Theobald: Analyst 67288 (1942).

(11) "Instrucción para el proyecto y la ejecución de obras de hormigón en masa o armado E.H.-73".

(12) J. Calleja: "Corrosión de las armaduras en hormigón armado y pretensado". Ultimos avances, n.os 123124 (1966).

(13) P. GARCIA DE PAREDES: "Durabilidad del hormigón de sus causas físico-químicas". Monografía vol. 232 I E.T.c.c.

(14) J. Nielsen: "Investigación de la resistencia de la pasta de cemento al ataque por sulfatos". Ultimos avances n. 311 (1967).

(15) J. Calleja : "Código de la buena práctica del hormigón". Ultimos avances, n. 144. 